\title{
233 STUDY OF SELECTED YOGA PRACTICES AS A REMEDY FOR LOW BACK PAIN IN IRANIAN WOMEN
}

Masoumeh Hassanpour Pune University, Pune, Maharashtra, India

10.1136/bjsm.2010.078725.233

Aim The purpose of this research was the study of selected yoga practices as a remedy for low back pain.

Subjects and methods The method of this study was experimental research and the samples were consisted of 30 women who were suffering of low back pain (30-40 aged). Thirty patients were randomised in two groups, experimental group $(\mathrm{N}=15)$ and control group $(\mathrm{N}=15)$. Experimental group accomplished yoga practices programme for 3 month, 5 days a week (any exercise programme wasn't planned for control group).

Results The information was analysed by the use of consequential, descriptive statistics SPSS software. Result showed that doing yoga practices had a significant reduction of low back pain in experimental group.

Conclusion Doing 3 month yoga practices had a positive effect on low back pain therefore we can use of yoga practices for low back pain as a remedy. 